\title{
Research \\ Cardiac troponin and skeletal muscle oxygenation in severe post-partum haemorrhage
}

\author{
Laurent Heyer ${ }^{1}$, Alexandre Mebazaa ${ }^{1}$, Etienne Gayat ${ }^{1}$, Matthieu Resche-Rigon², \\ Christophe Rabuel ${ }^{1}$, Eva Rezlan ${ }^{1}$, Anne-Claire Lukascewicz ${ }^{1}$, Catharina Madadaki ${ }^{1}$, \\ Romain Pirracchio ${ }^{1}$, Patrick Schurando ${ }^{1}$, Olivier Morel ${ }^{3}$, Yann Fargeaudou ${ }^{4}$ and Didier Payen ${ }^{1}$
}

\begin{abstract}
${ }^{1}$ AP-HP, Department of Anesthesiology and Critical Care Medicine, University Paris 7, Hôpital Lariboisière, 2 Rue Ambroise Pare, 75010 Paris, France 2Department of Biostatistics and Clinical Epidemiology, Saint-Louis University Hospital, Assistance Publique - Hôpitaux de Paris, INSERM U717, French National Institute for Health and Medical Research, Hopital Saint Louis, 12 Rue Claude Viellefaux, 75010 Paris, France ${ }^{3}$ Department of Radiology, University Paris 7, Hôpital Lariboisière, 2 Rue Ambroise Pare, 75010 Paris, France

${ }^{4}$ Department of Gynecology and Obstetrics, University Paris 7, Hôpital Lariboisière, 2 Rue Ambroise Pare, 75010 Paris, France
\end{abstract}

Corresponding author: dpayen1234@aol.com

Published: 30 November 2009

This article is online at http://ccforum.com/content/13/S5/S8

(C) 2009 BioMed Central Ltd
Critical Care 2009, 13(Suppl 5):S8 (doi:10.1186/cc8006)

intensive care unit (ICU) facilities [1-3]. We have previously suggested that, in addition to blood loss and the occurrence of haemorrhagic shock, increased plasma cardiac troponin I with electrocardiogram tracings suggestive of myocardial ischaemia may account for the morbidity associated with $\mathrm{PPH}$ [4]. Increased cardiac troponin was associated with low arterial blood pressure, increased heart rate $(>115$ beats/minute) and the use of catecholamines, suggesting an unbalanced myocardial oxygen consumption/delivery ratio. Whether the abnormal oxygen consumption/delivery ratio is only present in the myocardium or is a global phenomenon involving other organs, in severe PPH, remains to be elucidated.

The recent application of near-infrared spectroscopy to ICU patients allows continuous and non-invasive measurement of tissue haemoglobin oxygen saturation $\left(\mathrm{StO}_{2}\right)$ in the thenar eminence muscle $[5,6]$. $\mathrm{StO}_{2}$ was obtained via the ratio of oxygenated and deoxygenated haemoglobin measured by near-infrared spectroscopy $[7,8]$. A low $\mathrm{StO}_{2}$ value has been suggested to predict organ dysfunction $[9,10]$. In addition to static $\mathrm{StO}_{2}$ measurements, a forearm ischaemia/reperfusion test was recently applied in patients to allow dynamic measures of $\mathrm{StO}_{2}$ [11,12]. Inflation of a cuff around the patient's arm decreases $\mathrm{StO}_{2}$, which recovers when the cuff is released. The slope of $\mathrm{StO}_{2}$ recovery is altered in septic shock parturients [11,13]. Similar measurements have not been performed in haemorrhagic conditions.

We accordingly postulated that increased cardiac troponin might be associated with impaired oxygen consumption/

\section{Introduction}

Severe post-partum haemorrhage (PPH) remains one of the two leading causes of maternal death despite the use of

$\mathrm{ICU}=$ intensive care unit; $\mathrm{PPH}=$ post-partum haemorrhage; $S_{\text {occlusion }}=$ slope of tissue haemoglobin oxygen saturation decrease; $S_{\text {recovery }}=$ slope of tissue haemoglobin oxygen saturation ascent; $\mathrm{StO}_{2}=$ tissue haemoglobin oxygen saturation. 
delivery ratio in peripheral muscles. The haemoglobin tissue oxygen saturation of thenar muscle was therefore measured, before and after rescue therapy, in parturients admitted for blood loss related to $\mathrm{PPH}$.

\section{Parturients and methods}

Forty-two parturients with severe $\mathrm{PPH}$, defined as blood loss $>1,000 \mathrm{ml}$ associated with haemorrhagic shock [14-16], were included in the present study. All parturients had attended primary-care centres located within or around Paris (lle-deFrance region) and were transferred to our centre when locally available treatment options became inefficient in controlling the bleeding. Our tertiary-care centre is specialized in severe $\mathrm{PPH}$ with standardized management procedures including two major therapeutic options: when bleeding still persists, haemostatic surgery and/or an angiography with uterine embolization is performed; or, if the bleeding has stopped, the patient is monitored under intermediate care. Eight parturients with no PPH were also studied as a control group.

The following items were collected: medical history, obstetrical characteristics as obstetric procedure, details on the medical treatment, the type of surgical intervention performed, and the rate of blood transfusion. The following variables, previously described as indicators of bleeding intensity [4], were recorded during the first hour of ICU admission and at ICU discharge: the lowest systolic blood pressure and diastolic blood pressure, the highest heart rate, the lowest $\mathrm{pH}(\mathrm{IU})$, haemoglobin, prothrombin time (\%) and fibrinogen (normal range $=2$ to $4 \mathrm{~g} / \mathrm{l}$ ), and the highest lactate (normal range $=0.7$ to $2.1 \mathrm{mmol} / \mathrm{l}$ ) and troponin I level (normal range $<0.04 \mu \mathrm{g} / \mathrm{l}$ ).

\section{Quantification of haemoglobin saturation in the thenar eminence muscle}

Near-infrared spectroscopy technology uses the principles of light transmission and absorption to non-invasively measure the ratio of oxygenated and deoxygenated haemoglobin within arterioles, capillaries, and venules of thenar skeletal muscle [17]. The location of thenar eminence was chosen because of little interference with skin or fat tissue on the obtained signal and because interstitial oedema is limited $[7,18,19] . \mathrm{StO}_{2}$ was measured via a tissue spectrometer (InSpectra ${ }^{\mathrm{TM}}$ Model 325; Hutchinson Technology, Hutchinson, MN, USA) linked to a probe placed on the thenar eminence. This probe contains two fibre-optic endings with a spacing of $25 \mathrm{~mm}$, allowing a $23 \mathrm{~mm}$ in-depth measurement $[7,20,21] . \mathrm{StO}_{2}$ was continuously monitored and recorded using InSpectra ${ }^{\mathrm{TM}}$ software.

In addition to baseline measurements, $\mathrm{StO}_{2}$ was also measured during ischaemia-reperfusion tests performed in all our parturients. Measurement consisted of a cessation of forearm blood flow induced by a rapid pneumatic cuff inflation above the elbow to a pressure $50 \mathrm{mmHg}$ above the systolic arterial pressure. During this no-flow phase, thenar $\mathrm{StO}_{2}$
Figure 1

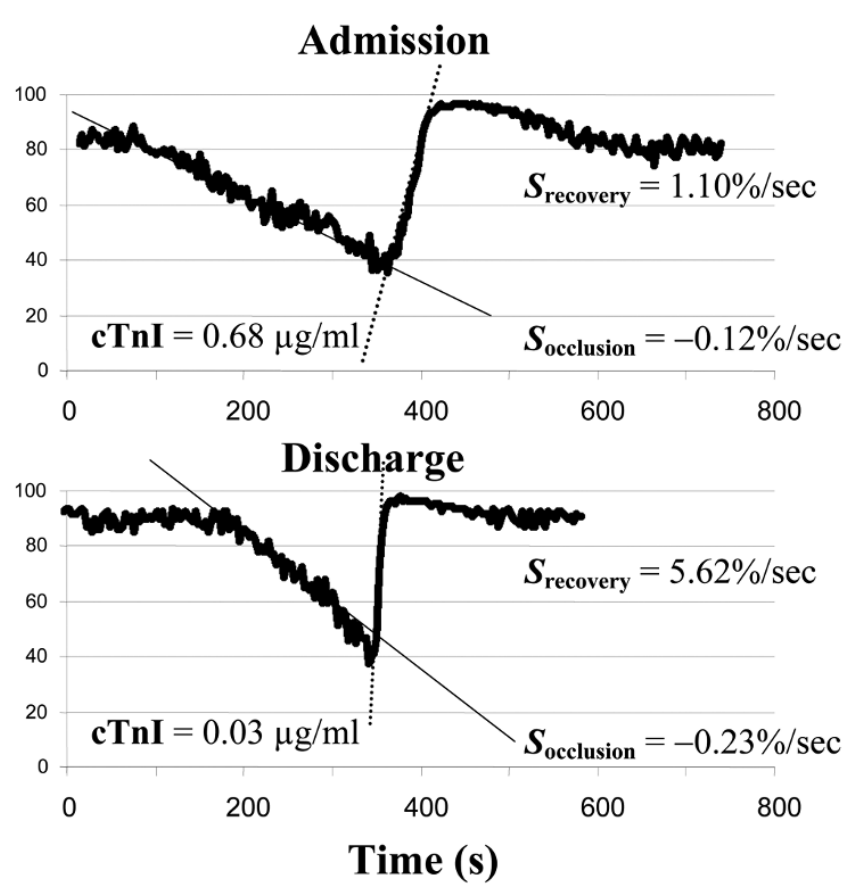

Thenar muscle tissue haemoglobin oxygen saturation in a patient hospitalized for severe post-partum haemorrhage. Representative example of thenar muscle tissue haemoglobin oxygen saturation $\left(\mathrm{StO}_{2}\right)$ at admission and at intensive care unit discharge in the same patient. Set of measurements: $\mathrm{StO}_{2}$ at baseline, during cuff inflation ( $\left.S_{\text {occlusion }}\right)$ and after cuff release (reperfusion phase, $S_{\text {recovery }}$ ). cTnl, cardiac troponin I (normal range $<0.04 \mu \mathrm{g} / \mathrm{l}$ ).

declines; when it reached a value of $40 \%$, the pneumatic cuff was immediately released. Figure 1 shows a representative example of an $\mathrm{StO}_{2}$ tracing during forearm ischaemiareperfusion tests in one parturient. This test allowed one to measure: during the forearm no-flow phase, the slope of $\mathrm{StO}_{2}$ decrease $\left(S_{\text {occlusion }}\right)$ that was previously described as an index of forearm muscular oxygen consumption [22,23]; and, after the cuff release, the slope of $\mathrm{StO}_{2}$ ascent $\left(S_{\text {recovery }}\right)$, an index of re-oxygenation capabilities of thenar skeletal muscle. Both slopes were calculated from numerical values using the least-square linear regression method. Of note, we choose $40 \%$ as a target to release the pneumatic cuff - instead of 3 minutes - because this level is safe, and because altered oxygen consumption in diseased patients might markedly alter $\mathrm{StO}_{2}$ at 3 minutes, which may influence the recovery slope of $\mathrm{StO}_{2}$. The stability of the thenar skin temperature and the absence of muscular contraction were checked during measurements.

The baseline thenar $\mathrm{StO}_{2}$ and changes following the forearm ischaemia-reperfusion test were recorded twice: at ICU admission, at the time of haemorrhagic shock; and immediately before ICU discharge, 12 to 24 hours after the control of genital bleeding. 
The protocol was approved by the Ethics Committee of the French Society of Intensive Care (CE-SRLF 07-185).

\section{Statistical analysis}

Data are summarized as frequencies and percentages for categorical variables. Quantitative variables are presented as the median (25th to 75th percentiles) or as the mean \pm standard deviation - except for $S_{\text {recovery }}$, for which a histogram is given.

Comparisons between measurements at admission and at the time bleeding was stopped were performed using Wilcoxon paired tests.

Univariate associations between plasma troponin I level $>0.04 \mu \mathrm{g} / \mathrm{l}$ and variables at admission were assessed using the logistic regression model and Wald tests. All factors with $P<0.05$ in the univariate analysis were included in a multiple logistic regression model. Variable selection was performed using a backward procedure. Odds ratios with their 95\% confidence intervals are presented as a measure of association. Furthermore, the receiver operating characteristic curve of $S_{\text {release }}$ was used to detect association with troponin I level $>0.04 \mu \mathrm{g} /$; the area under the curve is presented.

All tests were two-sided at the 0.05 significance level. Analyses were performed using the R statistical package [24].

\section{Results}

\section{Demographic data and management of post-partum haemorrhage}

Data from 42 consecutive parturients admitted for $\mathrm{PPH}$ are presented in Table 1. Twenty-three parturients were successfully managed medically and 19 parturients needed emergency invasive procedures: two had an immediate hysterectomy and 17 underwent angiography with a subsequent arterial embolization (predominantly in uterine arteries), which was successful for 15 of them and the last two parturients needed a combined hysterectomy and arterial embolization. Parturients required a median of 3 ( 0 to 7 ) units red blood cells. All parturients survived with a length of stay in our centre (intermediate care/ICU) of 2.1 (1.3 to 4.1 ) days.

\section{Haemodynamics, biology and haemoglobin tissue oxygen saturation}

Table 2 shows the impact of blood loss on the haemodynamic and biological parameters measured at admission. This includes low blood pressure, elevated heart rate, low haemoglobin $(7.1(6.3$ to 8.7$) \mathrm{g} / \mathrm{dl})$, increased serum lactate at $2.8 \pm 1.3 \mathrm{mmol} / \mathrm{l}$ (normal range $=0.7$ to $2.1 \mathrm{mmol} / \mathrm{l}$ ) and increased serum cardiac troponin I in 24/42 parturients $(0.43 \pm 0.60 \mu \mathrm{g} / \mathrm{l}$, while $<0.04 \mu \mathrm{g} / \mathrm{l}$ in the other 18 parturients). The three parturients requiring catecholamines all had an increased troponin I level. Control parturients $(n=8)$ had stable haemodynamics and haemoglobin at 10.8 (10.5 to 11.0$) \mathrm{g} / \mathrm{dl}$.
Table 1

\begin{tabular}{lc} 
Patient characteristics & \\
\hline Characteristic & Value \\
\hline Age $^{\mathrm{a}}$ & 34 (30 to 36) \\
Gravidity & 2 (1 to 3) \\
Parity & 2 (1 to 3) \\
Mode of delivery & \\
$\quad$ Vaginal & $28(67 \%)$ \\
$\quad$ Caesarean section & $14(33 \%)$ \\
$\quad$ Forceps & $10(24 \%)$ \\
Mode of treatment in our centre & \\
$\quad$ Medical management alone & $23(55 \%)$ \\
Embolization & $17(40 \%)$ \\
Hysterectomy & $4(10 \%)$ \\
Sulprostone & $40(95 \%)$ \\
Catecholamines & $3(7 \%)$ \\
Red blood cells (units) & $3(0$ to 7$)$ \\
Mechanical ventilation & $8(19 \%)$ \\
\hline
\end{tabular}

Data are presented as the median (interquartile range) or $n$ (\% of total); $n=42$. aSeven patients had both general and regional

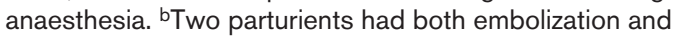
hysterectomy. ${ }^{c}$ Total including before admission and the care unit stay in our centre.

At admission, haemoglobin tissue oxygen saturation showed an initial $\mathrm{StO}_{2}$ at $82 \%$ (78 to $86 \%$ ), $S_{\text {occlusion }}$ at $-0.25 \%$ / second ( -0.33 to $-0.19 \% /$ second) and $S_{\text {recovery }}$ at $4.5 \% /$ second (2.4 to $6.0 \%$ /second). Control parturients had $\mathrm{StO}_{2}$ at $88 \%$ (80 to $90 \%), S_{\text {occlusion }}$ at $-0.44 \%$ /second $(-0.66$ to $-0.44 \% /$ second) and $S_{\text {recovery }}$ at $7.6 \%$ /second (5.9 to $9.5 \%$ / second) (all $P<0.0001$ versus admission for severe $\mathrm{PPH}$ ). Figure 2 shows that $S_{\text {recovery }}$ at admission exerted a bimodal distribution in our 42 severe $\mathrm{PPH}$ parturients, with the threshold at $3 \% /$ second. Figure 2 also shows that $S_{\text {recovery }}$ $<3 \% /$ second was associated with $87 \%$ of troponin-positive patients while $S_{\text {recovery }}>3 \%$ /second was associated with only $37 \%$ of troponin-positive patients $(P<0.002)$. The receiver operating characteristic curve confirms that the $S_{\text {recovery }}$ threshold of $3 \% /$ second had the optimal sensitivity and specificity for the association with increased cardiac troponin (Figure 3). Of note, neither baseline $\mathrm{StO}_{2}$ nor $S_{\text {occlusion }}$ showed a similar bimodal distribution or was associated with levels of cardiac troponin (data not shown).

Table 2 shows that the actions taken to control genital tract bleeding restored haemodynamic and biological parameters and improved all measured parameters of $\mathrm{StO}_{2}\left(S_{\text {occlusion }}\right.$ and $S_{\text {recovery }}$ ). Figure 1 shows a representative example of improvement of both $S_{\text {occlusion }}$ and $S_{\text {recovery }}$ after bleeding was controlled by uterine embolization. 
Table 2

\begin{tabular}{|c|c|c|c|}
\hline Variable & At admission & Intensive care unit discharge & $P$-value \\
\hline \multicolumn{4}{|l|}{ Hemodynamic } \\
\hline Systolic blood pressure $(\mathrm{mmHg})$ & 106 (100 to 120$)$ & $122(110$ to 130$)$ & 0.005 \\
\hline Diastolic blood pressure $(\mathrm{mmHg})$ & 53 (45 to 66$)$ & 60 (50 to 69$)$ & 0.28 \\
\hline Heart rate (beats/minute) & 105 (90 to 134$)$ & 90 (70 to 100$)$ & 0.0002 \\
\hline \multicolumn{4}{|l|}{ Biology } \\
\hline $\mathrm{pH}(\mathrm{IU})$ & 7.37 (7.34 to 7.42$)$ & 7.42 (7.40 to 7.43$)$ & 0.0004 \\
\hline Lactate $(\mathrm{mmol} / \mathrm{l})$ & 2.4 (1.9 to 3.5$)$ & 1.4 (0.9 to 2.0$)$ & $<0.0001$ \\
\hline Haemoglobin (g/dl) & 7.1 (6.3 to 8.7$)$ & 8.2 (7.4 to 9.6$)$ & $<0.0001$ \\
\hline Prothrombin time (\%) & 63 (48 to 73 ) & 83 (74 to 94$)$ & $<0.0001$ \\
\hline Fibrinogen $(\mathrm{g} / \mathrm{l})$ & 2.1 (1.3 to 2.9$)$ & 3.6 (3.1 to 4.5$)$ & $<0.0001$ \\
\hline Cardiac troponin I ( $\mu \mathrm{g} / \mathrm{l})$ & 0.07 (0.02 to 0.18$)$ & 0.02 (0.02 to 0.08$)$ & 0.0008 \\
\hline \multicolumn{4}{|l|}{ NIRS measurements } \\
\hline $\mathrm{StO}_{2}(\%)$ & 82 (78 to 86$)$ & $87(80$ to 91$)$ & $<0.0001$ \\
\hline$S_{\text {occlusion }}(\% /$ second $)$ & $-0.25(-0.33$ to -0.19$)$ & $-0.32(-0.4$ to -0.23$)$ & 0.001 \\
\hline$S_{\text {recovery }}(\% /$ second $)$ & $4.5(2.4$ to 6.0$)$ & $5.8(4.6$ to 7.0$)$ & 0.0003 \\
\hline
\end{tabular}

Data presented as median (interquartile range); $n=42$. $P$-values were calculated using the Wilcoxon test. NIRS, near-infrared spectroscopy; $S_{\text {occlusion }}$, slope of tissue haemoglobin oxygen saturation decrease; $S_{\text {recovery }}$ slope of tissue haemoglobin oxygen saturation ascent; $\mathrm{StO}_{2}$, tissue haemoglobin oxygen saturation.

\section{Factors associated with increased cardiac troponin in post-partum haemorrhage parturients}

Univariate analysis showed that, among all measured parameters, heart rate $>115 /$ minute and muscular $S_{\text {recovery }}<3 \%$ / second, both measured at admission, were independently associated with increased cardiac troponin. The adjusted odds ratios were 5.0 (95\% confidence interval $=1.1$ to 21.9 , $P=0.03$ ) for heart rate $>115 /$ minute and 11.2 (95\% confidence interval $=2.1$ to $60.0, P=0.005$ ) for muscular $S_{\text {recovery }}$ $<3 \% /$ second. Furthermore, multivariate analysis showed that $S_{\text {recovery }}<3 \%$ /second at admission was strongly associated with increased cardiac troponin, with an odds ratio of 8.8 (95\% confidence interval $=1.6$ to $49.0, P=0.01$ ).

\section{Discussion}

The present study confirms the high incidence of increased cardiac troponin and, more importantly, showed for the first time a simultaneous deterioration in all measured parameters of $\mathrm{StO}_{2}$, at admission, in our $\mathrm{PPH}$ parturients.

$\mathrm{StO}_{2}$ was assessed using the near-infrared spectroscopy device that measures the ratio of oxygenated and deoxygenated haemoglobin within arterioles, capillaries, and venules of skeletal muscle with little influence from skin or other tissues $[7,20]$. The thenar $\mathrm{StO}_{2}$ was previously described to be $87 \pm 6 \%$ in healthy volunteers and $80 \pm 12 \%$ in patients with blood loss [10]. Our study results are in line with those published results as we found a median $\mathrm{StO}_{2}$ of $88 \%$ (80 to $90 \%$ ) in control parturients, and of $82 \%(78$ to $86 \%$ ) at admission and $87 \%$ ( 80 to $91 \%$ ) before ICU discharge in our $\mathrm{PPH}$ parturients.
During the forearm ischaemia-reperfusion test [22,25], the slope of $\mathrm{StO}_{2}$ decrease during the no-flow phase $\left(S_{\text {occlusion }}\right.$; Figure 1) was previously described as an index of thenar oxygen consumption $[23,26]$. In our study, $S_{\text {occlusion }}$ was impaired at admission when parturients were haemodynamically unstable (-0.25\%/second) compared with $-0.32 \% /$ second at discharge. This suggests that thenar oxygen consumption was low at admission and increased over time when bleeding was controlled and haemodynamics improved.

The slope of thenar $\mathrm{StO}_{2}$ ascent after the ischaemic no-flow challenge $\left(S_{\text {recovery }}\right)$ was used to quantify the post-ischaemic reoxygenation capabilities in the thenar muscle $[27,28]$. Our study shows that $S_{\text {recovery }}$ was low in our PPH parturients at admission and improved towards levels measured in parturients with no PPH. As described above, the low $S_{\text {recovery }}$ at admission cannot be explained by a high oxygen consumption in the thenar muscle of our parturients. Accordingly, the low $S_{\text {recovery }}$ measured at admission is probably explained by an impaired post-ischaemic reserve of oxygen delivery in the thenar muscle at the time of admission for $\mathrm{PPH}$.

We have previously described a high incidence of increased cardiac troponin that was associated with low blood pressure, high heart rate, low haemoglobin level, T-wave inversions and echocardiography changes in severe $\mathrm{PPH}$ [4]. Several hypotheses, including subendocardial ischaemia due to a mismatch between myocardial oxygen supply and demand [29,30], have been proposed - but the mechanisms by which these features cause increases in cardiac troponin in the absence of acute coronary syndrome in $\mathrm{PPH}$ par- 
Figure 2

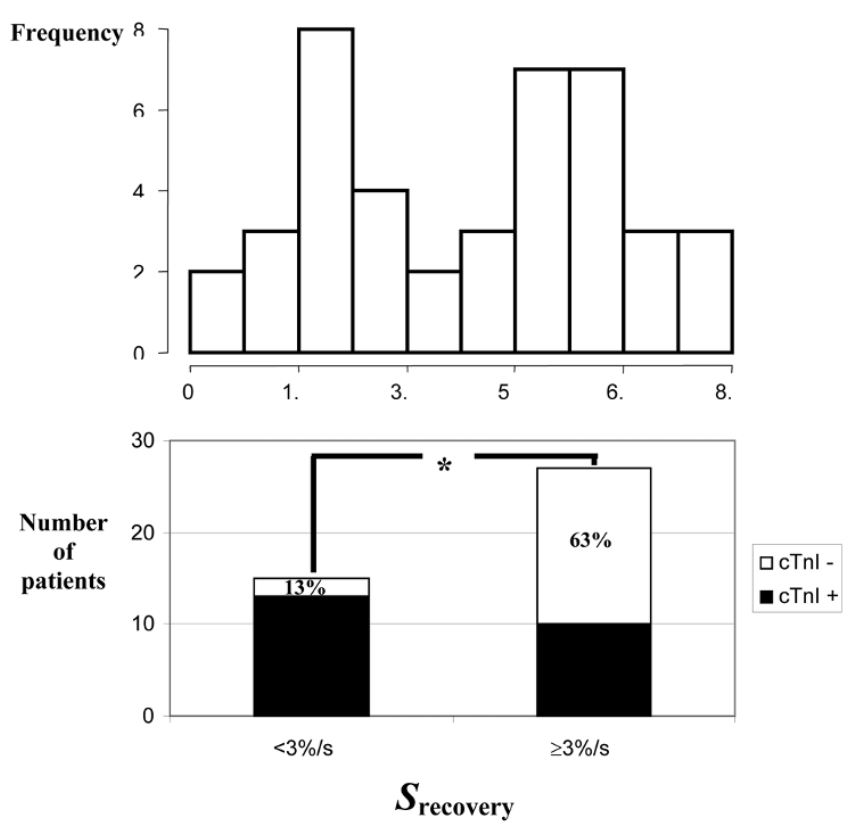

Tissue haemoglobin oxygen saturation ascent at admission. Upper panel: bimodal distribution of the baseline ascent slope $\left(S_{\text {recovery }}\right)$. Lower panel: most parturients (16/18) with negative cardiac troponin I (cTnl) showed $S_{\text {recovery }}>3 \% /$ second, only $13 \%$ had negative cTnl. ${ }^{\star} P<0.002$.

turients remain uncertain. Our study revealed that increased cardiac troponin was strongly associated with muscular $S_{\text {recovery }}<3 \% /$ second and not with baseline $\mathrm{StO}_{2}$ or with $S_{\text {occlusion. }}$ Muscular $S_{\text {recovery }}<3 \% /$ second was even more strongly associated (odds ratio $>10$ ) with increased cardiac troponin than a high heart rate in our $\mathrm{PPH}$ parturients. This might suggest - if the increased cardiac troponin was related to a mismatch between myocardial oxygen supply and demand, and if simultaneous impairments observed in the myocardium and in peripheral muscle were related to similar mechanisms - that increased cardiac troponin was rather due to an impaired myocardial oxygen supply than to an increased oxygen demand. This hypothesis needs further evaluation.

In summary, our study confirmed the high incidence of increased cardiac troponin and demonstrated a simultaneous impairment in the reserve of oxygen delivery to the peripheral muscles in our severe PPH parturients when admitted with unstable haemodynamics. These data confirm that haemodynamic management in this patient subpopulation should focus on the early simultaneous restoration of both blood pressure and haemoglobin levels and, if possible, the reduction of tachycardia.

\section{Competing interests}

DP received honoraria from Hutchinson Company for lectures. The other authors declare that they have no competing interests.
Figure 3

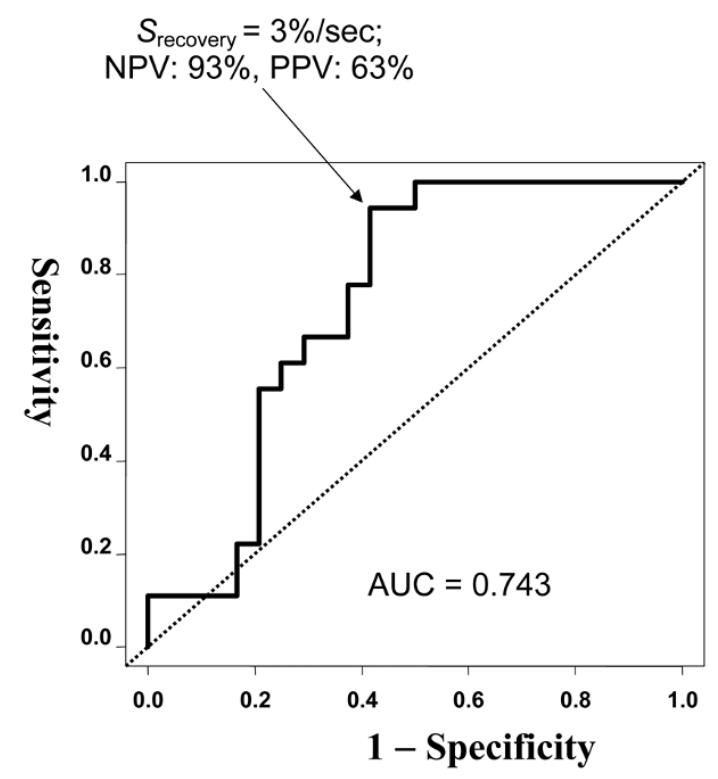

Association of tissue haemoglobin oxygen saturation ascent with plasma troponin I. Receiver operating characteristic curve of tissue haemoglobin oxygen saturation ascent $\left(S_{\text {recovery }}\right)$ to association with plasma troponin I. AUC, area under the curve; NPV, negative predictive value; PPV, positive predictive value.

\section{Acknowledgements}

Support was provided to DP by the Ministère de l'Enseignement Supérieur et de la Recherche (EA 322) and a research Grant for Hutchinson Company.

This article is part of Critical Care Volume 13 Supplement 5: Tissue oxygenation $\left(\mathrm{StO}_{2}\right)$ in healthy volunteers and critically-ill patients. The full contents of the supplement are available online at http://ccforum. $\mathrm{com} / \mathrm{supplements/13/S5}$. Publication of the supplement has been supported with funding from Hutchinson Technology Inc.

\section{References}

1. Bouvier-Colle $M H$, Pequignot $F$, Jougla $E$ : Maternal mortality in France: frequency, trends and causes. J Gynecol Obstet Biol Reprod (Paris) 2001, 30:768-775.

2. Panchal S, Arria AM, Harris AP: Intensive care utilization during hospital admission for delivery: prevalence, risk factors, and outcomes in a statewide population. Anesthesiology 2000, 92: 1537-1544.

3. Panchal S, Arria AM, Labhsetwar SA: Maternal mortality during hospital admission for delivery: a retrospective analysis using a state-maintained database. Anesth Analg 2001, 93:134-141.

4. Karpati PC, Rossignol M, Pirot M, Cholley B, Vicaut E, Henry P, Kevorkian JP, Schurando P, Peynet J, Jacob D, Payen D, Mebazaa A: High incidence of myocardial ischemia during postpartum hemorrhage. Anesthesiology 2004, 100:30-36; discussion 35A.

5. Ikossi DG, Knudson MM, Morabito DJ, Cohen MJ, Wan JJ, Khaw L, Stewart CJ, Hemphill C, Manley GT: Continuous muscle tissue oxygenation in critically injured patients: a prospective observational study. J Trauma 2006, 61:780-788; discussion 788-790.

6. McKinley BA, Marvin RG, Cocanour CS, Moore FA: Tissue hemoglobin $\mathrm{O}_{2}$ saturation during resuscitation of traumatic shock monitored using near infrared spectrometry. J Trauma 2000, 48:637-642.

7. Mancini DM, Bolinger L, Li H, Kendrick K, Chance B, Wilson JR: Validation of near-infrared spectroscopy in humans. J Appl Physiol 1994, 77:2740-2747. 
8. Soller BR, Idwasi PO, Balaguer J, Levin S, Simsir SA, Vander Salm TJ, Collette H, Heard SO: Noninvasive, near infrared spectroscopic-measured muscle $\mathrm{pH}$ and $\mathrm{PO}_{2}$ indicate tissue perfusion for cardiac surgical patients undergoing cardiopulmonary bypass. Crit Care Med 2003, 31:2324-2331.

9. Cohn SM, Nathens AB, Moore FA, Rhee P, Puyana JC, Moore EE, Beilman GJ: Tissue oxygen saturation predicts the development of organ dysfunction during traumatic shock resuscitation. J Trauma 2007, 62:44-54; discussion 54-45.

10. Crookes BA, Cohn SM, Bloch S, Amortegui J, Manning R, Li P, Proctor MS, Hallal A, Blackbourne LH, Benjamin R, Soffer D, Habib F, Schulman Cl, Duncan R, Proctor KG: Can near-infrared spectroscopy identify the severity of shock in trauma patients? J Trauma 2005, 58:806-813.

11. Creteur J, Carollo T, Soldati G, Buchele G, De Backer D, Vincent $\mathrm{JL}$ : The prognostic value of muscle $\mathrm{StO}_{2}$ in septic patients. Intensive Care Med 2007, 33:1549-1556.

12. Pareznik R, Knezevic R, Voga G, Podbregar M: Changes in muscle tissue oxygenation during stagnant ischemia in septic patients. Intensive Care Med 2006, 32:87-92

13. Sair M, Etherington PJ, Peter Winlove C, Evans TW: Tissue oxygenation and perfusion in patients with systemic sepsis. Crit Care Med 2001, 29:1343-1349.

14. Drife J: Management of primary postpartum haemorrhage. $\mathrm{Br}$ J Obstet Gynaecol 1997, 104:275-277.

15. Jouppila P: Postpartum haemorrhage. Curr Opin Obstet Gynecol 1995, 7:446-450.

16. Mousa HA, Walkinshaw S: Major postpartum haemorrhage. Curr Opin Obstet Gynecol 2001, 13:595-603.

17. Soller BR, Ryan KL, Rickards CA, Cooke WH, Yang Y, Soyemi OO, Crookes BA, Heard SO, Convertino VA: Oxygen saturation determined from deep muscle, not thenar tissue, is an early indicator of central hypovolemia in humans. Crit Care Med 2008, 36:176-182.

18. Poeze M: Tissue-oxygenation assessment using near-infrared spectroscopy during severe sepsis: confounding effects of tissue edema on $\mathrm{StO}_{2}$ values. Intensive Care Med 2006, 32: 788-789.

19. van Beekvelt MC, Borghuis MS, van Engelen BG, Wevers RA, Colier WN: Adipose tissue thickness affects in vivo quantitative near-IR spectroscopy in human skeletal muscle. Clin Sci (Lond) 2001, 101:21-28.

20. Myers DE, Anderson LD, Seifert RP, Ortner JP, Cooper CE, Beilman GJ, Mowlem JD: Noninvasive method for measuring local hemoglobin oxygen saturation in tissue using wide gap second derivative near-infrared spectroscopy. J Biomed Opt 2005, 10:034017.

21. Lima A BJ: Noninvasive monitoring of peripheral perfusion. Intensive Care Med 2005, 31:1316-1326.

22. Hampson NB, Piantadosi CA: Near infrared monitoring of human skeletal muscle oxygenation during forearm ischemia. J Appl Physiol 1988, 64:2449-2457.

23. Skarda DE, Mulier KE, Myers DE, Taylor JH, Beilman GJ: Dynamic near-infrared spectroscopy measurements in patients with severe sepsis. Shock 2007, 27:348-353.

24 R statistical package [http://www.R-project.org]

25. Van Beekvelt MC, Colier WN, Wevers RA, Van Engelen BG: Performance of near-infrared spectroscopy in measuring local $\mathrm{O}_{2}$ consumption and blood flow in skeletal muscle. J Appl Physiol 2001, 90:511-519.

26. Girardis M, Rinaldi L, Busani S, Flore I, Mauro S, Pasetto A: Muscle perfusion and oxygen consumption by near-infrared spectroscopy in septic-shock and non-septic-shock patients. Intensive Care Med 2003, 29:1173-1176.

27. McCully KK, Smith S, Rajaei S, Leigh JS, Jr, Natelson BH: Muscle metabolism with blood flow restriction in chronic fatigue syndrome. J App/ Physio/ 2004, 96:871-878.

28. Wariar R, Gaffke JN, Haller RG, Bertocci LA: A modular NIRS system for clinical measurement of impaired skeletal muscle oxygenation. J Appl Physiol 2000, 88:315-325.

29. Metzler H, Gries M, Rehak P, Lang T, Fruhwald S, Toller W: Perioperative myocardial cell injury: the role of troponins. $\mathrm{Br} J$ Anaesth 1997, 78:386-390.

30. Pirracchio R, Cholley B, De Hert S, Solal AC, Mebazaa A: Diastolic heart failure in anaesthesia and critical care. $\mathrm{Br} J$ Anaesth 2007, 98:707-721. 